\title{
ADOÇÃO DA VARIEDADE DE MILHO MATUBA PELOS PEQUENOS PRODUTORES DO DISTRITO DE SUSSUNDENGA, MOÇAMBIQUE
}

\author{
Sérgio Feliciano Come* \\ José Ambrósio Ferreira Neto**
}

RESUMO: O estudo analisou a adoção da variedade melhorada de milho Matuba pelos pequenos produtores agrários do distrito de Sussundenga. Os dados foram coletados através da administração de entrevistas semiestruturadas a 160 pequenos produtores no mês de julho de 2014. O modelo de regressão Logit foi usado para determinar as variáveis com efeito significativo na adoção da variedade Matuba. Um conjunto de variáveis socioeconômicas e institucionais foi usado para compor as variáveis explicativas no modelo em referência. Os resultados mostram que apenas cerca de $40 \%$ dos produtores adotaram o milho Matuba. As variáveis estatisticamente significativas na adoção de milho Matuba foram o nível escolar, o sexo do chefe do agregado familiar e a prática de outras atividades diferentes da agricultura. Por outro lado, o acesso aos serviços de extensão agrária, o acesso ao crédito agrário, a idade do chefe do agregado familiar, o tamanho do agregado familiar e a pertença a uma associação ou grupo de produtores não foram significativos na adoção de Matuba.

PALAVRAS-CHAVE: Pequenos produtores; Tecnologias agrárias; Milho Matuba.

\section{THE USE OF MATUBA MAIZE VARIET Y BY SMALL PRODUCERS IN THE DISTRICT OF SUSSUNDENGA, MOZAMBIQUE}

ABSTRACT: Improved variety of Matuba maize used by small farmers in the district of Sussundenga, Mozambique, is analyzed. Data were collected by 160 half-structured interviews of small farmers in July 2014. Logit regression model determined variables with significant effect in the adoption of the Matuba variety. A set of social, economic and institutional variables was employed to compose the model's explicative variables. Results show that approximately $40 \%$ of farmers planted Matuba maize and the statistically significant variables were schooling level, gender of the chief of the family compound and the practice of other activities besides agriculture. On the

Docente da Universidade Zambeze afeto na Faculdade de Engenharia Ambiental e dos Recursos Naturais-Chimoio, Moçambique; Doutorando em Extensão Rural na Universidade Federal de Viçosa; Bolsista do Instituto de Bolsa de Estudos do Ministério da Educação e Desenvolvimento Humano, Moçambique.

E-mail: sergiofcome@gmail.com

** Doutor em Sociedade, Desenvolvimento e Agricultura - Universidade Federal Rural do Rio de Janeiro; Docente da Universidade Federal de Viçosa 
other hand, access to agrarian extension services, access to agrarian credit, age of the chief of family compound and belonging to an association or group of producers were not significant in the choice.

KEY WORDS: Small farmers; Agrarian technologies; Matuba maize.

\section{INTRODUÇÃO}

Os principais instrumentos de planificação e orientação da agricultura em Moçambique (exemplo do Plano Estratégico do Desenvolvimento do Sector AgrárioPEDSA 2011-2017, Plano Director de Extensão 2007-2016 e o Plano Nacional de Investimento do Sector Agrário 2013-2017) defendem que as tecnologias agrícolas melhoradas são ferramentas essenciais para a melhoria do desempenho do setor da agricultura. Assim, durante os últimos anos, o Ministério da Agricultura e Segurança Alimentar (ex-Ministério da Agricultura) envidou esforços para que a adoção das tecnologias agrícolas melhoradas aumentasse. Apesar desses esforços, a adoção destas continua baixa em Moçambique. Por exemplo, menos de $7 \%$ das famílias que cultivam o milho, um cultivo básico, usam variedades melhoradas. Apesar desta constatação, poucos estudos procuram explicar a lentidão na adoção de tecnologias agrícolas melhoradas em Moçambique (UAIENE, 2011).

Em relação ao milho, Sánchez et al., (2011) afirmam que este é um cultivo muito importante em Moçambique, sendo o primeiro em termos de número de pequenos produtores ${ }^{3}$ que o praticam, área cultivada e produção de energia para o trabalho. Deste modo, o aumento da produção deste cereal é uma das estratégias mais importantes para o alcance da segurança alimentar em Moçambique (CAVANE;

3 Embora possa existir diferenças no que a literatura denomina de pequeno produtor e agricultor familiar, percebe-se que em Moçambique, os dois termos são usados como sinônimos para designar o mesmo sujeito. Para Abramovay (1997), a agricultura familiar é aquela em que a gestão, a propriedade e a maior parte do trabalho vêm de indivíduos que mantêm entre si laços de sangue ou de casamento. Porém, o autor reconhece que esta definição não é unânime entre os autores. No caso de Moçambique, o Instituto Nacional de Estatística (INE, 2011) designa o sujeito praticante da agricultura como pequeno produtor ou produtor familiar se a sua exploração apresentar as seguintes características: uma área não superior a 25 hectares sendo que destes, menos de 10 hectares de área é ocupada com cultivos permanentes e anuais ou menos 05 hectares com cultivos irrigados. No que diz respeito aos efetivos pecuários, o pequeno produtor ou agricultor familiar deve ter menos de dez cabeças de gado bovino ou menos de 50 pequenos ruminantes e suínos ou menos de 2.000 aves. 
DONOVAN, 2011).

A província de Manica, situada na região Central de Moçambique, é apontada como sendo uma das maiores produtoras de milho no país. Dentro desta província, o distrito de Sussundenga tem contribuído bastante para a produção global do milho. Por exemplo, o relatório da Direcção Provincial de Agricultura de Manica (DPAM), datado de 2013, mostra que na campanha agrícola 2012/2013, o distrito de Sussundenga contribuiu com cerca de $26 \%$ da produção global de milho nesta província. A produtividade deste cereal, na mesma campanha agrícola foi de cerca de 2,55 ton/ha, contra as 1,9 ton/ha do global da província de Manica. Apesar de a produtividade do milho ao nível do distrito ser alta em relação à média da província, esta é considerada baixa tendo em conta que o potencial deste cultivo é estimado em 4.5 ton/ha (MINAG, 2010). Dos vários fatores que concorrem para a baixa produtividade agrária no distrito de Sussundenga, destaca-se a fraca adoção das tecnologias melhoradas em especial nas pequenas explorações (CASTIGO, 2000). Porém, a análise de fatores associados à adoção de tecnologias agrárias em Moçambique e no distrito de Sussundenga, em particular, é uma questão ainda pouca estudada. Dentre as várias tecnologias difundidas pelos serviços de extensão rural no distrito de Sussundenga, destaca-se o uso de sementes melhoradas de milho pelo fato de estas apresentarem mais produtividade e serem tolerantes a diferentes condições de estresse. Deste modo, este estudo objetiva analisar os fatores que determinam a adoção da variedade melhorada de milho Matuba no distrito de Sussundenga.

O milho Matuba é uma variedade de polinização aberta (designada por Open-Pollinated Variety-OPV em inglês). Esta apresenta um ciclo muito curto, o que significa menos riscos de perda da cultura e tem bons rendimentos ( 5 a 6 ton/ ha). A variedade Matuba foi produzida e desenvolvida pelo Instituto de Investigação Agrária de Moçambique e aprovada em 2005.

Para além do presente capítulo (introdução), o trabalho é composto por mais quatro capítulos nomeadamente: revisão bibliográfica, metodologia, resultados e discussão e considerações finais.

\section{REVISÃO BIBLIOGRÁFICA}

A maioria dos estudos sobre a adoção de novas tecnologias ou inovações toma como base Rogers (2003), um dos pioneiros nas teorias de difusão e adoção de 
novas tecnologias. Segundo Rogers (2003), uma inovação é qualquer objeto, prática ou ideia percebida como novo por um potencial adotante.

\subsection{MODELOS DE ADOÇÃO DE TECNOLOGIAS AGRÁRIAS}

Negatu e Parikh (1999), citados por Chirwa (2005) e Rogers (2003), agruparam os modelos de adoção de tecnologias agrárias pelos pequenos produtores em três grupos:

a) Modelo de difusão de inovações ou de transferência de tecnologias. Neste modelo uma tecnologia é transferida da sua fonte para o pequeno produtor por intermédio de agentes de extensão, considerando-se que a difusão da tecnologia depende das características do produtor.

b) Modelo dos constrangimentos econômicos. Este toma a visão de que os produtores têm diferentes rendas e que a distribuição dessas rendas determina a adoção das tecnologias.

c) Modelo das características da tecnologia e o contexto do potencial adotante. Este assume que as características da tecnologia e as condições agroecológicas, socioeconômicas e circunstâncias institucionais dos produtores jogam papel fundamental na adoção das tecnologias.

\subsection{SÍNTESE DE ALGUNS ESTUDOS SOBRE A ADOÇÃO DAS VARIEDADES MELHO- RADAS DE MILHO}

Kafle (2010) fez um resumo dos principais estudos sobre a adoção de variedades melhoradas de milho em países africanos e asiáticos nos 15 últimos anos anteriores a 2010. Os mesmos apontam uma série de características socioeconômicas, agroecológicas e percepção dos produtores como os fatores mais significativos na adoção das variedades melhoradas de milho. Entre estas variáveis, o contato com os serviços de extensão rural, o nível escolar do produtor, o acesso ao crédito por parte do produtor, o tamanho do campo foram os fatores mais significativos na adoção das variedades melhoradas de milho nos diferentes países. 
Mugisha e Diiro (2010) analisaram a adoção das variedades melhoradas de milho nos distritos de Nakasongola e Soroti em Uganda. A recolha de dados foi feita por meio de entrevistas a 151 agricultores. Os dados coletados foram analisados pelo modelo de regressão binária probit. O estudo aponta elevada adoção das variedades de melhoradas de milho tendo como principal fator o acesso aos serviços de extensão rural. Porém, a principal ameaça da adoção das variedades de milho naqueles distritos é a seca.

Cavane e Donovan (2011) avaliaram a adoção das variedades de milho SC 513 em Machipanda e Vandúzi, província de Manica, Moçambique. Uma amostra aleatória de 293 produtores foi usada para a coleta de dados e posteriormente analisados pelo modelo de regressão logística. Os fatores significativos na adoção da variedade SC 513 foram as condições agroecológicas, o conhecimento dos produtores, tratamentos de produção e aspetos de comercialização do milho.

Kalinda, Tembo e Kuntashula (2014) determinaram os fatores associados à adoção de variedades de milho na Zâmbia. O modelo de regressão Tobit foi usado para o alcance do objetivo do trabalho. As expetativas acerca do preço e rendimento das variedades, tamanho do campo, sexo do chefe do agregado familiar e pertença a associação de produtores foram significativos na adoção das variedades melhoradas de milho.

Desta revisão constatou-se que os estudos de adoção das variedades de milho empregam na sua maioria modelos de regressão para determinar os fatores significativos na adoção deste insumo. Os fatores associados à adoção têm sido ligados às características socioeconômicas do produtor, fatores agroecológicos e percepção dos produtores sobre o insumo em referência.

\section{METODOLOGIA}

\subsection{CARACTERIZAÇÃO DA ÁREA DO ESTUDO}

Com uma superfície de $7057 \mathrm{Km}^{2}$, o distrito de Sussundenga localiza-se na zona central da província de Manica, sendo limitado a norte pelos distritos de 
Gondola e Manica ${ }^{4}$, a oeste pelo Zimbabwe, a sul pelo distrito de Mossurizi e a este pelo distrito de Búzi pertencente à província de Sofala (MAE, 2005). Estimase que o distrito de Sussundenga possuia cerca de 157,018 habitantes no ano de 2013 (GPM, 2013). Segundo Mae (2005), a população economicamente ativa do distrito é estimada em 41.000 pessoas. Destas, cerca de 36.890 (89\%) praticam a agricultura que é a principal atividade econômica do distrito. Esta atividade é praticada maioritariamente por pequenos produtores que fazem consorciação dos seguintes cultivos: milho, mapira, mandioca e feijão nhemba. Verifica-se também a prática de cultivos de rendimento como o algodão, tabaco e girassol em regime de monocultivo. Estes sistemas são complementados pela criação de gado bovino, caprino e aves (MAE, 2005).

\subsection{PROCEDIMENTOS DE COLETA DE DADOS}

Os dados foram coletados por meio de entrevistas semiestruturadas a 160 pequenos produtores do distrito de Sussundenga distribuídos segundo o Quadro 1. Porém, antes da condução das entrevistas, foi aplicado um teste para se verificar a objetividade do guião de entrevista, que resultou na melhoria deste. Este foi aplicado a 12 pequenos produtores de Sussundenga Sede. De referir que as entrevistas tiveram lugar no mês de julho de 2014.

Quadro 1. Distribuição dos produtores entrevistados em função da sua localização dentro do distrito de Sussundenga

\begin{tabular}{|l|c|c|}
\hline Região & Número de produtores entrevistados & Percentagem (\%) \\
\hline Sussundenga Sede & 32 & 20 \\
\hline Munhinga & 38 & 23,75 \\
\hline Muoha & 56 & 35 \\
\hline Rotanda & 34 & 21,25 \\
\hline Total & 160 & 100 \\
\hline
\end{tabular}

Fonte: Adaptado pelo autor da pesquisa (2014)

4 Manica é nome de uma província localizada na zona central de Moçambique e também de um distrito localizado na província do mesmo nome. 


\subsection{ANÁLISE DE DADOS}

Os dados relacionados com a caracterização dos produtores entrevistados foram analisados por meio da estatística descritiva (frequências percentuais) para as variáveis sexo, nível de escolaridade, acesso ao crédito, pertença à uma associação ou grupo de produtores agrários, acesso aos serviços de extensão agrária, tamanho do agregado familiar e prática de outras atividades diferentes da agricultura. Para a determinação dos fatores de adoção de sementes melhoradas foi usado o modelo de regressão Logit. Segundo Beshir e Wegary, (2014), os fatores que explicam a adoção de tecnologias podem ser estimados usando os modelos Logit, Probit e Tobit. Porém, Peng, Lee e Ingresoll (2002) afirmam que quando as variáveis independentes contínuas são incluídas no modelo de regressão, o modelo Logit é o mais apropriado para explicar e testar a hipótese da relação entre a variável resposta do tipo categórica e uma ou várias variáveis explicativas de natureza categórica ou contínua. No presente estudo, o modelo Logit foi eleito uma vez que algumas das variávies explicativas são categóricas e outras são contínuas enquanto que a variável resposta $y$ é categórica binária assumindo o valor 1 se o produtor usar as sementes melhoradas de milho e 0 , caso contrário.

\subsection{ESPECIFICAÇÃO DO MODELO DE REGRESSÃO LOGÍSTICA USADO NO ESTU- DO}

Segundo Peng, Lee e Ingresoll, (2002), o modelo de regressão Logit tem a forma:

$$
\operatorname{logit}(Y)=\ln \left(\frac{\pi}{1-\pi}\right)=\alpha+\beta X
$$

$\varpi=$ Probabilidade $(\mathrm{Y}=$ evento de interesse $\mid \mathrm{X}=\mathrm{x}$, para um valor específico de $\mathrm{X})=\frac{\theta^{\alpha+\beta x}}{1+\theta^{\alpha+\beta \alpha}}$

em que ๗ é a probabilidade de ocorrência do evento de interesse no caso concreto, a adoção ou não da variedade de milho Matuba, $\alpha$ é o interceto de $y$, $\beta$ é o coeficiente da regressão, e é a base do logarítmo natural sendo igual a 2.71828. A variável $x$ pode ser categórica ou contínua, mas $y$ é sempre categórica. Estendendo 
o modelo de regressão logística simples para a múltipla, pode ser construído um modelo complexo que no caso do presente trabalho tem a seguinte forma:

$$
\pi=\frac{e^{\alpha+\beta 1 X 1+\beta 2 X 2+\beta 3 X 3+\beta 4 X 4+\beta 5 X 5+\beta 6 X 6+\beta 7 X 7+\beta 8 X 8+\beta 9 X 9}}{1+e^{\alpha+\beta 1 X 1+\beta 2 X 2+\beta 3 X 3+\beta 4 X 4+\beta 5 X 5+\beta 6 X 6+\beta 7 X 7+\beta 8 X 8+\beta 9 X 9}}
$$

$\beta_{1}$ a $\beta_{9}$ representam os coeficientes das variáveis explicativas, $X_{1}$ a $X_{9}$ são as variáveis explicativas do modelo e $\alpha$ representa o intercepto de y. A significância dos coeficientes das variáveis explicativas foi determinada por meio do teste $t$ Student em que a hipótese nula é de que $\beta=0$, contra a hipótese alternativa de que $\beta \neq 0$.

Quadro 2. Caracterização das variáveis explicativas usadas no modelo de regressão

\begin{tabular}{|l|l|}
\hline Variável & Tipo \\
\hline $\mathrm{X}_{1}$ (Sexo do chefe do agregado familiar) & Dummy (1 se for homem e 0 se for mulher) \\
\hline $\mathrm{X}_{2}$ (Idade do chefe do agregado familiar) & Contínua (anos) \\
\hline $\mathrm{X}_{3}$ (Tamanho do agregado familiar) & Contínua \\
\hline $\begin{array}{l}\mathrm{X}_{4} \text { (Nível escolar chefe do agregado } \\
\text { familiar) }\end{array}$ & Contínua (anos de escolaridade) \\
\hline $\begin{array}{l}\mathrm{X}_{5} \text { (Experiência do chefe do agregado } \\
\text { familiar na prática da agricultura) }\end{array}$ & Contínua (anos) \\
\hline $\begin{array}{l}\mathrm{X}_{6} \text { (Prática de outras atividades } \\
\text { diferentes da agricultura) }\end{array}$ & $\begin{array}{l}\text { Dummy (1 se praticar outra atividade e } 0 \text { caso } \\
\text { contrário) }\end{array}$ \\
\hline $\mathrm{X}_{7}$ (Acesso à extensão agrária) & Dummy (1 se sim e 0 caso contrário) \\
\hline $\begin{array}{l}\mathrm{X}_{8} \text { (Pertença à associação de produtores } \\
\text { agrários) }\end{array}$ & Dummy (1 se sim e 0 caso contrário) \\
\hline $\mathrm{X}_{9}$ (Acesso ao crédito agrário) & Dummy (1 se sim e 0 caso contrário) \\
\hline
\end{tabular}

Fonte: Adaptado pelo autor da pesquisa (2014)

As variáveis descritas no Quadro 2 foram selecionadas tomando como base estudos anteriores sobre a adoção de tecnologias agrárias incluindo variedades melhoradas de milho (KAFLE, 2010; CAVANE; DONOVAN, 2011; MUGISHA; DIIRO, 2010). 
Os dados foram analisados com o auxílio do Pacote Estatístico para as Ciências Sociais (Statistical Package for Social Sciences-SPSS em inglês) versão 20.

\subsection{LIMITAÇÕES DO ESTUDO}

Na sua maioria, os produtores têm um nível escolar muito baixo, o que impossibilitou a comunicação em língua portuguesa e a indicação do tamanho das suas parcelas. Aliado a esta situação, os dados foram recolhidos com escassez de recursos o que se traduziu na impossibilidade de fazer medições ou cálculos do tamanho das parcelas dos produtores e da renda das famílias. De referir que estudos anteriores usaram modelos que incluem estas variáveis como preditoras na adoção de tecnologias agrárias incluindo variedades melhoradas de milho. Deste modo, não se afasta a hipótese de os resultados deste estudo serem influenciados em parte pela não inclusão destas variáveis no modelo de regressão.

O estudo foi realizado numa altura morta em termos da atividade agrária de sequeiro, o que impossibilitou a confrontação das respostas dos produtores com o que existia nos seus campos.

\section{RESULTADOS E DISCUSSÃO}

\subsection{CARACTERÍSTICAS SOCIOECONÔMICAS DOS RESPONDENTES}

O Quadro 3 mostra as características dos produtores entrevistados.

Quanto ao sexo do chefe dos agregados familiares dos entrevistados, o mesmo evidencia uma predominância de famílias chefiadas por mulheres $(56,3 \%)$ sendo que as restantes $43,1 \%$ das famílias são chefiadas por homens. A proximidade do distrito de Sussundenga à cidade de Chimoio (capital da província de Manica) pode ser um dos fatores que contribuem para que muitas famílias sejam chefiadas diretamente por mulheres. É provável que os homens (que poderiam chefiar as famílias agricultoras) passem parte significativa do ano ou das suas vidas em trabalhos sazonais ou permanentes na cidade de Chimoio pelo fato de esta oferecer mais oportunidades de emprego do que as zonas rurais como o distrito de Sussundenga. Esta hipótese é ainda sustentada por Sitoe (2010) ao afirmar que nas Zonas Verdes 
da cidade de Maputo -capital de Moçambique, a existência de homens que pratica a agricultura é interpretada como consequência da falta de emprego.

Em termos de idades dos chefes de agregados familiares, metade das famílias é chefiada por jovens (entre 16 e 35 anos).

Quadro 3. Distribuição dos produtores entrevistados segundo as suas características

\begin{tabular}{|c|c|c|}
\hline Variáveis & Categorias & Frequências \\
\hline \multirow{2}{*}{$\begin{array}{l}\text { Sexo do chefe do agregado } \\
\text { familiar }\end{array}$} & Masculino & $70(43,7)$ \\
\hline & Feminino & $90(56,3)$ \\
\hline \multirow{3}{*}{$\begin{array}{l}\text { Idade do chefe do agregado } \\
\text { familiar }\end{array}$} & 16 a 35 anos & $80(50)$ \\
\hline & 36 a 60 anos & $36(22,5)$ \\
\hline & Mais de 60 anos & $44(27,5)$ \\
\hline \multirow{5}{*}{$\begin{array}{l}\text { Nível escolar do chefe do } \\
\text { agregado familiar }\end{array}$} & Nenhum & $38(23,75)$ \\
\hline & Primário de $1^{\circ}$ grau & $50(31,25)$ \\
\hline & Primário de $2^{\circ}$ grau & $36(22,5)$ \\
\hline & Secundário básico & $30(18,75)$ \\
\hline & Pré-universitário & $6(3,75)$ \\
\hline \multirow{3}{*}{$\begin{array}{l}\text { Estado civil do chefe do } \\
\text { agregado familiar }\end{array}$} & Casado(a) & $131(81,9)$ \\
\hline & Solteiro(a) & $14(8,8)$ \\
\hline & Viúvo(a) & $15(9,4)$ \\
\hline \multirow{2}{*}{$\begin{array}{l}\text { Pertença a uma associação ou } \\
\text { grupo de produtores agrários }\end{array}$} & Sim & $25(15,6)$ \\
\hline & Não & $135(84,4)$ \\
\hline \multirow[t]{2}{*}{ Acesso à extensão rural } & $\operatorname{Sim}$ & $52(32,5)$ \\
\hline & Não & $108(67,5)$ \\
\hline \multirow[t]{2}{*}{ Acesso ao crédito agrário } & Sim & $7(4,4)$ \\
\hline & Não & $153(95,6)$ \\
\hline \multirow{2}{*}{$\begin{array}{l}\text { Prática de outras atividades } \\
\text { econômicas diferentes da } \\
\text { agricultura }\end{array}$} & Sim & $85(53,1)$ \\
\hline & Não & $75(46,9)$ \\
\hline
\end{tabular}

Fonte: Trabalho de Campo (2014). Os números entre parênteses representam percentagens. $\mathrm{N}=160$. 
Segundo o quadro ainda em referência, os chefes de agregados familiares apresentam baixo nível escolar, sendo que cerca de 77,5\% destes possuem nível escolar não superior ao primário de segundo grau (7 anos de escolaridade).

Sobre o estado civil dos chefes dos agregados familiares dos produtores entrevistados, o quadro ilustra que cerca de $81,9 \%$ dos entrevistados são casados ou vivem maritalmente, $9,4 \%$ são viúvos e $8,8 \%$ são solteiros.

A maioria dos chefes dos agregados familiares dos produtores $(84,4 \%)$ não pertence à associações ou grupos de produtores agrários contra 15,6\% que fazem parte das associações.

Sobre o acesso à extensão rural ${ }^{5}$, apenas $32,5 \%$ dos produtores ou suas famílias têm enquanto que a maioria $(67,5 \%)$ não o tem. Embora a percentagem dos produtores com acesso à extensão rural seja maior comparada à referida por Come e Cavane (2014) de 7,24\% e 7,35\% no distrito de Manhiça nos anos de 2010 e 2011, esta pode ser considerada baixa, uma vez que o desejável seria que pelo menos metade dos produtores tivesse acesso à extensão rural.

Apenas $4,4 \%$ dos produtores entrevistados afirmaram que já tiveram acesso ao crédito agrário. Esta situação confirma os resultados de Trabalho de Inquérito Agrícola 2010 (CUNGUARA; GARRETT, 2011). Segundo estes autores, o acesso ao crédito agrário por parte dos pequenos produtores em Moçambique é muito reduzido.

No que diz respeito a pluratividade, mais de metade dos produtores entrevistados (cerca de 53\%) exercem para além da agricultura outras atividades econômicas. Destas, destaca-se a prática do comércio de produtos agrícolas, de produtos alimentares e de vestuário nos mercados locais e a prestação de serviços de carpintaria e latoaria. Para além destas atividades, 10 dos produtores afirmaram que recebem remessas de cônjuges e ou de filho(a)s que trabalham em outros locais como as cidades de Chimoio e Beira.

5 Os serviços de extensão rural, considerados neste estudo, são os aconselhamentos que os produtores recebem dos agentes de extensão agrária (públicos, privados ou de parceiros) sobre a produção agrícola. Segundo Relatório das Actividades de Extensão, datado de 2014, as principais atividades desenvolvidas pela extensão rural no distrito de Sussundenga são a assistência técnica agrária às associações de produtores, realização de formações quinzenais sobre elaboração de planos e uniformização de pacotes tecnológicos, assistência na realização de banhos caracicidas (não encontrei este termo no dicionário) ao gado bovino, preparação e monitoria de Campos de Demonstração de Resultados (CDR), preparação e participação nas visitas de troca de experiências no âmbito das Escola na Machamba de Camponês (EMC). 


\subsection{DETERMINANTES DA ADOÇÃO DA VARIEDADE DE MILHO MATUBA}

Dos 160 produtores entrevistados, apenas 63 (39,4\%) produtores afirmaram cultivar a variedade de milho Matuba. Muitos dos não adotantes referiramse que não cultivam Matuba devido ao fato de não possuírem recursos financeiros para a compra de sementes melhoradas deste cultivo enquanto que outros alegaram que não optam por esta variedade uma vez que é facilmente infestada por pragas de armazém como o caso dos gorgulhos comparativamente às variedades locais.

O Quadro 4 mostra os fatores determinantes na adoção da variedade de milho Matuba.

A variável sexo do chefe do agregado familiar foi estatisticamente significativa para a adoção das sementes melhoradas de milho Matuba. Isto significa que há acesso diferenciado entre homens e mulheres produtores de milho no cultivo da variedade Matuba. Uaiene (2011), Nwakor et al., (2011) e Kalinda, Tembo e Kuntashula, (2014) encontraram também efeito significativo do sexo do chefe do agregado familiar na adoção de variedades melhoradas de milho em Moçambique, Nigéria e Zâmbia, respetivamente.

O nível escolar do chefe do agregado familiar foi estatisticamente significativo na predição da adoção da variedade de milho Matuba. Resultados semelhantes foram encontrados por Salifu e Salifu (2015), Kalinda, Tembo e Kuntashula (2014) e Lopes (2010) no município de Wa-Gana, na Zâmbia e em Moçambique, respetivamente.

Quadro 4. Resultados do modelo de regressão logit

(Continua)

\begin{tabular}{|l|c|c|}
\hline \multicolumn{1}{|c|}{ Variável explicativa (X) } & $\begin{array}{c}\text { Coeficiente da } \\
\text { variável } \mathbf{X}(\boldsymbol{\beta})\end{array}$ & Significância \\
\hline Sexo do chefe do agregado familiar & $0.932^{* *}$ & 0.019 \\
\hline Idade do chefe do agregado familiar & 0.015 & 0.425 \\
\hline Tamanho do agregado familiar & -0.023 & 0.691 \\
\hline Nível escolar do chefe do agregado familiar & $0.199^{* *}$ & 0.004 \\
\hline Experiência na prática da agricultura & -0.007 & 0.723 \\
\hline
\end{tabular}


(Conclusão)

\begin{tabular}{|l|c|c|}
\hline Prática de outras atividades econômicas & $0.753^{*}$ & 0.062 \\
\hline Acesso aos serviços de extensão rural & 0.108 & 0.728 \\
\hline $\begin{array}{l}\text { Pertença a uma associação ou grupo de } \\
\text { produtores agrários }\end{array}$ & 0.107 & 0.846 \\
\hline Acesso ao crédito agrário & 1.717 & 0.143 \\
\hline Interceto & -2.684 & 0.002 \\
\hline & & $\begin{array}{c}\mathrm{R}^{2} \text { de Cox e Snell } \\
=0.231\end{array}$ \\
\cline { 3 - 3 } & $\begin{array}{c}\mathrm{R}^{2} \text { de Nagelkerke } \\
=0.312\end{array}$ \\
\hline
\end{tabular}

Fonte: Autores da pesquisa (2014) $\quad$ ** significativo a 5\%, *significativo à 10\%

Outra variável estatisticamente significativa na adoção do milho Matuba foi a prática de outras atividades diferentes da agricultura. Assim, é provável que os produtores de milho estejam a usar recursos financeiros provenientes de outras atividades econômicas para a compra de insumos agrícolas, incluindo sementes melhoradas de milho Matuba.

Contrariamente ao que era esperado, as variáveis acesso à extensão, pertença à associação de produtores e acesso ao crédito agrário não foram significativas na adoção da variedade Matuba. Estudos anteriores mostraram inconsistência sobre o efeito destas variáveis na adoção de variedades melhoradas de milho. Kafle (2010) relatou efeito positivo e significativo destas variáveis na adoção de variedades melhoradas de milho. Alinhando com os resultados do presente estudo, Lopes (2010) relatou a não significância de acesso ao crédito e a pertença a associação de produtores na adoção das variedades melhoradas de milho em Moçambique. A não significância das variáveis em questão pode ser causada pelo fato de a extensão rural chegar a poucos produtores o que por sua vez pode fazer com que o trabalho realizado pelos extensionistas tenha efeito muito menor nas práticas diárias dos produtores. Por outro lado, o crédito agrário chega a um número muito reduzido de produtores. Tudo isto de certa forma pode acabar por enfraquecer a importância que era de se esperar da extensão rural e do crédito agrário. 
Outras variáveis não significativas foram a idade do chefe do agregado familiar, o tamanho do agregado familiar e a experiência do chefe do agregado familiar na prática da agricultura.

Embora a idade seja um fator muito importante na adoção de variedades melhoradas de milho, estudos anteriores mostraram inconsistência do efeito desta variável na adoção deste insumo (BESHIR; WEGARY, 2014). Alinhando com os resultados do presente estudo, Kaliba, Hugo e Wilfred (2000), Alene, Poonyth e Hassan (2000) e Cavane e Donovan (2011) encontram a não significância da idade na adoção das variedades melhoradas de milho. Por outro lado, Kalinda, Tembo e Kuntashula, (2014) encontraram significância da idade na adoção de variedades melhoradas de milho. Assumindo que a idade e a experiência do produtor são variáveis diretamente proporcionais, o efeito da experiência do produtor na adoção pode ser comparado com o da idade do chefe do agregado familiar (LOPES, 2010). Alguns autores afirmam que quanto mais a idade de um produtor aumenta, aumenta também a sua resistência para adotar outras tecnologias.

Sobre o tamanho dos agregados familiares, Cavane e Donovan (2011) afirmam que este joga importante papel na oferta da mão de obra e que a adoção de novas variedades requer mais força de trabalho. Assume-se que as famílias largas oferecem mais força de trabalho para a demanda de trabalho requerido na produção de variedades melhoradas de milho (FEDER et al., 1985 apud CAVANE; DONOVAN, 2011). Porém, uma vez que neste estudo não se determinou a proporção das pessoas economicamente ativas nos agregados familiares, torna-se difícil explicar a influência do tamanho do agregado familiar na adoção do milho Matuba. Segundo Kafle (2010), é difícil generalizar a influência do tamanho do agregado familiar na adoção das tecnologias agrárias.

\section{CONSIDERAÇÕES FINAIS}

O estudo analisou a adoção da variedade de milho Matuba pelos pequenos produtores do distrito de Sussundenga.

Os resultados mostram a predominância de famílias chefiadas por mulheres apresentando um nível escolar muito baixo sendo de destacar o fato de 
77,5\% destes serem iletrados (nível escolar inferior a 7 anos de escolaridade). Destas constatações, surge a necessidade de se desenhar alternativas para a popularização do ensino no seio dos pequenos produtores agrários com vista ao aumento do nível escolar destes.

A maioria dos pequenos produtores do distrito de Sussundenga não tem acesso aos serviços de extensão rural, ao crédito agrário e não pertence às associações de produtores.

A variedade de milho nas regiões de estudo foi adotada por cerca de $40 \%$ dos pequenos produtores. A não adoção de milho Matuba pela maioria dos pequenos produtores se deve a falta de recursos financeiros para a compra de sementes e a suposta susceptibilidade desta variedade às pragas de armazém. Deste modo, encorajam-se as autoridades de agricultura a promoverem a realização de feiras agrícolas para a venda de sementes a preços subsidiados por forma a permitir maior acesso desta pelos pequenos produtores.

Do modelo de regressão, verificou-se que o sexo do chefe do agregado familiar, o nível escolar do chefe do agregado familiar e a prática de outras atividades diferentes da agricultura foram as variáveis significativas na adoção da variedade Matuba pelos pequenos produtores.

$\mathrm{O}$ acesso à extensão rural, a pertença à associação de produtores, a idade e a experiência do chefe do agregado familiar dos produtores não tiveram efeito significativo na adoção de milho Matuba.

Devido ao fato de o estudo não ter conseguido incorporar todas as variáveis no seu modelo de regressão, recomenda-se que as futuras pesquisas sobre a adoção de tecnologias agrárias incorporem variáveis como renda familiar, tamanho da área alocada à produção agrícola, aspetos de mercado dos fatores e do produto em referência e a percepção dos produtores sobre a tecnologia em estudo.

\section{AGRADECIMENTOS}

Os autores do artigo agradecem os estudantes Hermenegildo Botha, Germano Amenda, Miguel Bota, Jacinto Ndarissone e Isidro Limome pela sua participação na coleta de dados. 


\section{REFERÊNCIAS}

ABRAMOVAY, R. Paradigmas do Capitalismo Agrário em questão. São Paulo, Unicamp, Hucitec, 1992. Uma nova extensão para a agricultura familiar. In: SEMINÁRIO NACIONAL DE ASSISTÊNCIA TÉCNICA E EXTENSÃO RURAL, 1997. Anais... Brasília, 1997. p. 29 (texto para discussão).

ALENE, A.; POONYTH D.; HASSAN, R. Determinants of Adoption and Intensity of Use of Improved Maize Varieties in the Central Highlands of Ethiopia: A Tobit Analysis. Agrekon, v. 4, p. 633-643, 2000.

BESHIR, B.; WEGARY, D. Determinants of smallholder farmers' hybrid maize adoption in the drought prone Central Rift Valley of Ethiopia, African Journal of Agricultural Research, v. 9, n.17, p. 1334-1343, 2014.

CASTIGO, P. Análise da produção agrícola no distrito de Sussundenga. 2000. 49f. Monografia (Graduação em Geografia) - Faculdade de Letras e Ciências Sociais, Universidade Eduardo Mondlane, Maputo, 2000.

CAVANE, E.; DONOVAN, C. Farmers' attitude and adoption of improved maize varieties and chemical fertilizers in Mozambique. Journal of International Agricultural and Extension Education, v. 18, n. 3, p. 5-21, 2011.

CHIRWA, E, Adoption of fertilize and hybrid seeds by smallholder maize farmers in southern Malawi. Develop. South Africa, v. 22, p. 1-12, 2005.

COME, S.; CAVANE, E. A extensão rural pública: percepções dos produtores das associações agrícolas de Manhiça Sede, Moçambique. Revista de Extensão e Estudos Rurais, Viçosa. v. 3, n. 1, p. 123-153, 2014.

CUNGUARA, B.; GARRET, J. O Sector Agrário em Moçambique: Análise situacional, constrangimentos e oportunidades para o crescimento agrário. In: DIÁLOGO sobre a Promoção de Crescimento Agrário em Moçambique, Maputo. 2011.

DPAM - Direcção Provincial da Agricultura de Manica. Balanço das campanhas agrícolas 2011/12 e 2012/13. 2013. Não publicado. 
GOVERNO DO DISTRITO DE SUSSUNDENGA. Relatório Trimestral das Actividades Desenvolvidas pela Rede de Extensão: $2^{\circ}$ Trimestre de 2014. Sussundenga, (Não publicado), 2014.

GPM - Governo da Província de Manica. Plano Económico e Social, Chimoio, (Não publicado), 2013.

INSTITUTO NACIONAL DE ESTATÍSTICA - INE. Censo Agro-Pecuário 2009-2010: Resultados Definitivos, Maputo. 2011.

KAFLE, B. Determinants of adoption of improved maize varieties in developing countries: a review. International Research Journal of Applied and Basic Sciences, v.1, n.1, p. 1-7, 2010.

KALIBA A.; HUGO, V.; WILFRED, I. Factors Affecting Adoption of Improved Maize Seeds and Use of Inorganic Fertilizer for Maize Production in the Intermediate and Lowland Zones of Tanzania, Journal of Agricultural and Applied Economics, v. 32, n. 1, 2000.

KALINDA. T.; TEMBO. E.; KANTASHULA, E. Adoption of Improved Maize Seed Varieties in Southern Zambia. Asian Journal of Agricultural Sciences, v. 6, n. 1, p. 33-39, 2014.

LOPES, H. Adoption of improved maize and common bean varieties in Mozambique. 2010. Dissertação (Mestrado em Agriculture, Food and Resources Economic) - Michigan State University, 2010.

MAE - Ministério da Administração Estatal. Perfil do distrito de Sussundenga, Província de Manica, 2005. Disponível em: <www.metier.co.mz>. Acesso em: jul. 2015.

MINAG - Ministério da Agricultura. Plano Estratégico Para o Desenvolvimento do Sector Agrário 2010-2019, Maputo, 2010.

MUGISHA, J.; DIIRO, G. Explaining the Adoption of Improved Maize Varieties and its 
Effects on Yields among Smallholder Maize Farmers in Eastern and Central Uganda, Middle-East Journal of Scientific Research. v. 5, n. 1, p. 6-13, 2010.

NWAKOR et al., Socio-economic factors affecting adoption of improved cassava varieties among farmers in Abia State. Journal of Agriculture and Social Research, Nigeria, v. 11, n.1, p 63-71, 2011.

PENG. C.; LEE, K.; INGRESOLL, G. An Introduction to Logistic Regression Analysis and Reporting. Indiana University-Bloomington. Journal of Education Research, v. 96, n. 1, p. 2-14, 2002.

ROGERS, E. Diffusion of innovations. $5^{\text {th }}$ Edition. Nova York: Free Press, 2003.

SALIFU, H.; SALIFU, K. Determinants of Farmers Adoption of Improved Maize Varieties in the Wa Municipality, American International Journal of Contemporary Research, v. 5, n. 4, p. 27-35, 2015.

SÁNCHEZ, et al. Milho: uma cultura de boa nutrição e de muita energia. Maputo, 2011.

SITOE, T. A Extensão Agrícola e as Escolas na Machamba do Camponês em Moçambique: O caso da Produção Hortícola nas Zonas Verdes da Cidade de Maputo. Revista UNIARA, v. 13, n. 2, p. 50-69, 2010.

UAIENE, R. Determinantes para a Adopção de Tecnologias Agrícolas em Moçambique. Maputo. 2011.

Recebido em: 11 de fevereiro de 2016 Aceito em: 25 de setembro de 2016 